\title{
Correction to: Tissue-based assessment of hazard posed by mercury and selenium to wild fishes in two shallow Chinese lakes
}

\author{
Ruiqing Zhang ${ }^{1} \mathbb{C} \cdot$ Fengchang $\mathrm{Wu}^{2} \cdot$ John P. Giesy $y^{2,3,4,5}$
}

Published online: 20 October 2021

C Springer-Verlag GmbH Germany, part of Springer Nature 2021

Correction to: Environmental Science and Pollution Research (2019) 26:15989-15999 https://doi.org/10.1007/s11356-019-04504-8

The correct Fig. 1 is presented in this paper.

The original article can be found online at https://doi.org/10.1007/ s11356-019-04504-8

Ruiqing Zhang

zruiqing2007@126.com

Fengchang Wu

wufengchang@vip.skleg.cn

1 School of Ecology and Environment, Inner Mongolia University, Hohhot 010021, Inner Mongolia, China

2 State Key Laboratory of Environmental Criteria and Risk Assessment, Chinese Research Academy of Environmental Sciences, Beijing 100012, China

3 Department of Veterinary Biomedical Sciences and Toxicology Centre, University of Saskatchewan, Saskatoon, Saskatchewan, Canada

4 Zoology Dept. and Center for Integrative Toxicology, Michigan State University, East Lansing, MI 48824, USA

5 Department of Environmental Science, Baylor University, Waco, TX, USA 
Fig. 1 Map of the study areas, including Tai Lake and Baiyangdian Lake

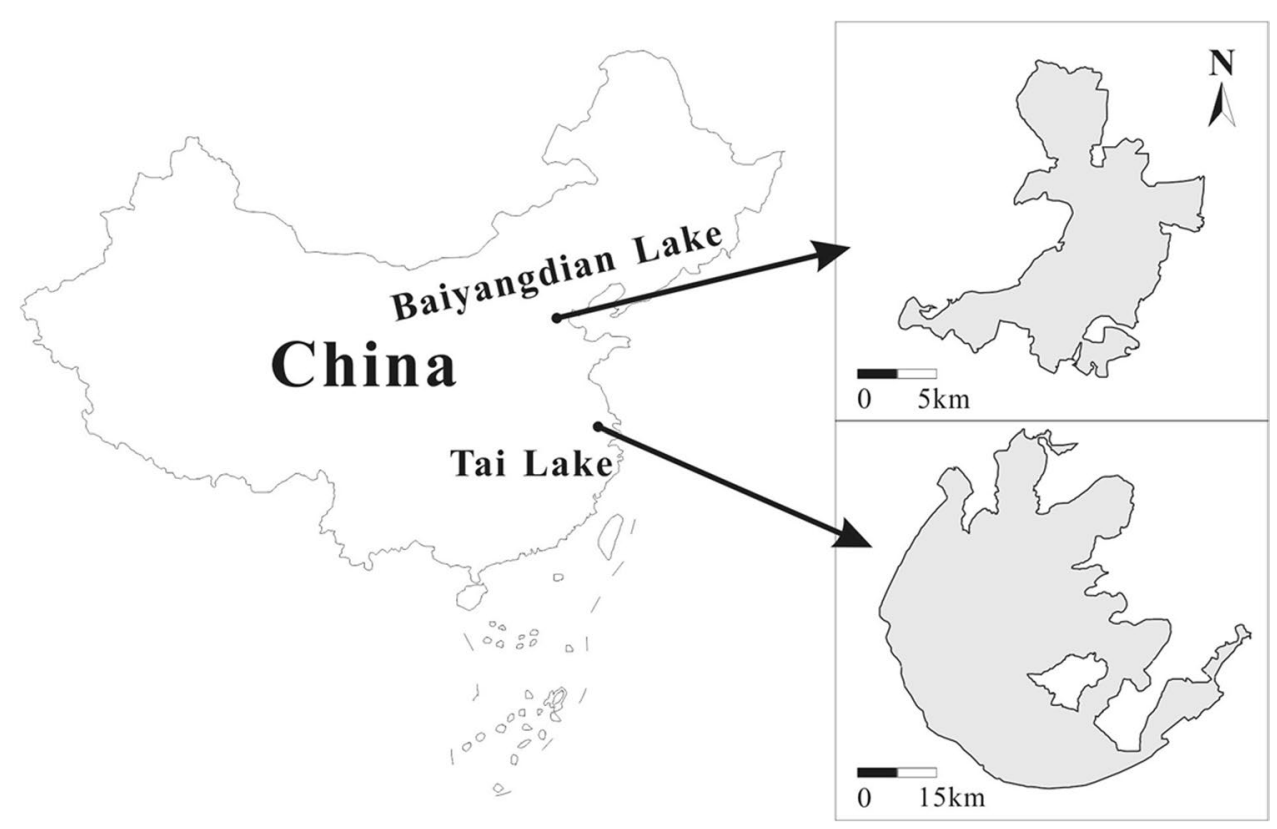

Publisher's note Springer Nature remains neutral with regard to jurisdictional claims in published maps and institutional affiliations. 